\section{Nutritional Protocol for Osteoarthrosis (Degenerative Joint Disease)}

\author{
Emmett James Hughes \\ University of Bridgeport, Bridgeport, CT, USA
}

\author{
Corresponding author: \\ Emmett James Hughes \\ ” ehughes@bridgeport.edu \\ University of Bridgeport, Bridgeport, CT, \\ USA.
}

Tel: (632) 988-6445

Citation: Hughes EJ. Nutritional Protocol for Osteoarthrosis (Degenerative Joint Disease). J Clin Nutr Diet. 2016, 2:4.

\section{Introduction}

Osteoarthrosis (OA) is sometimes referred to as osteoarthritis, degenerative arthritis, or degenerative joint disease. It is characterized by degeneration of the articular cartilage and subchondral bone. It can result in joint deformities, with characteristic Bouchard's nodes in the proximal phalangeal joints of the fingers and Heberden's nodes in the distal joints of the fingers. The predictable symptoms include joint pain and stiffness, becoming more chronic over time. Other symptoms commonly included joint swelling, weakness and/or paresthesias in the extremities and decreased range of motion. Typically, joints in the fingers, thumb, knees, spine, and hips can be involved. It can also be the result of trauma to a single joint leading to degeneration of the joint years later. Abnormal cartilage, congenital deformities of joint(s), infection of a joint, crystal deposition and/or other arthritic conditions can lead to OA of the joint.

Approximately 27 million people in the U.S. suffer from OA [1]. As people age, the prevalence of OA increases. In people under 45, it's more common in men. After 45, it is more common in women. The knee is the most common joint to be affected. Conventional treatments include exercise, acetaminophen, NSAIDs, opioids, injecting anesthetics, hyaluronan (hyaluronic acid), or plateletrich plasma, or joint replacement. One peculiar finding is the lack of correlation between the severity of the disease as seen on radiographs and the patient's symptoms.

\section{Conventional Pharmaceutical Treatment}

Conventional treatment includes non-steroidal anti-inflammatory drugs. While their use is widespread, there is some evidence that long-term use may inhibit the synthesis of the cartilage matrix and accelerate the deterioration of cartilage [2-5]. However, there is some evidence that is contradictory. There are some studies that demonstrate that the anti-inflammatory effects of low-dose aspirin slow the progression on cartilage loss in OA [6]. Additionally, there are significant risks associated with the use of NSAIDs; including gastrointestinal bleeding and cardiovascular events.

\section{Manual Medicine}

Musculoskeletal joint derangement and misalignments have been demonstrated to play a role in the development of OA. In one study involving 230 patients with varus deformities of the knee, the was a four-fold increase in degenerative arthritis in the knee when compared to the general population [7]. Joint alignment, muscle strength nutritional status, previous trauma and mid-stance loads all seem to contribute to the development of OA [8,9]. Manipulative and manual therapy has both been shown to increase range of motion, decrease pain, and decrease the need for pain medicine [10-12]. One study concluded that the cost of treatment was reduced when manual therapy and exercise were integrated into the treatment plan [13]. Swimming and isometrics have been identified as superior to other types of exercise for the treatment of OA [14-15]. Decreased stability and balance have been demonstrated to have a negative effect on OA, particularly in the knee [16]. Conversely, strengthening the muscles controlling the hip and knee is an effective way to mitigate some of the disabling symptoms associated with $\mathrm{OA}$ in the lower extremity [17]. 


\section{Diet}

Diet should focus on the decrease of inflammation, as well as improving insulin sensitivity and achieving ideal body weight. Obesity is a major risk factor for the development of OA in the knees and hips. There is considerable evidence linking metabolic syndrome (syndrome $X$ ) with inflammatory cytokines implicated in OA [18-21]. Insulin stimulates chondrocytes and chondroblasts to secrete proteoglycans, which are essential to the proper function of cartilage. Decreased sensitivity to insulin has a detrimental effect on cartilage [22]. Combining weight loss and exercise is known to decrease the risk of developing $O A$, as well as reducing the symptoms of $O A$ and improving function [23].

General guidelines for diet include a plant-based diet, relying on fresh fruits and vegetables, as well as whole grains, fatty fish and lean meats. Dairy products and gluten-containing grains are known to be allergenic in many people, and therefore should be minimized or eliminated from the diet. The Mediterranean diet has been show to significantly improve the symptoms of OA [24]. Certain individuals may benefit from eliminating nightshades (tomatoes, white potatoes, peppers, and eggplant) from the diet, most likely because of an individual's sensitivity to these plants. One study looked at Diosgenin, a steroidal saponin found in nightshades. Diosgenin possesses diverse biological activities including anti-inflammatory properties. It has been shown to inhibit the synthesis of inflammatory mediators, such as prostaglandin E2 and interleukins. Therefore, there is a possibility that these plants may actually be beneficial for OA [25].

\section{Supplements}

\section{Glucosamine sulfate}

Glucosamine sulfate is a relatively small molecule, consisting of glucoseandanamine. One of themostcommonmonosaccharaides, it is found in the exoskeletons of crustaceans and arthropods, and in the cell walls of fungi. It is known to stimulate the production of Glycosaminoglycan's (GAGs), a major component of cartilage. Aging appears to reduce the individual's ability to manufacture glucosamine $[26,27]$. Oral supplementation with derivatives of $\mathrm{N}$-acetyl glucosamine has been shown to have superior cartilage protection over glucosamine sulfate supplements [28]. Glucosamine sulfate supplements have demonstrated efficacy in treating OA, as well as a wide-margin of safety [29]. While not all studies have proven the positive effects of glucosamine sulfate supplementation [30], the overwhelming majority of the studies support its use for treatment of OA [26-29,31-32], especially the crystalline form [33].

\section{Chondroitin sulfate}

Chondroitin sulfate is a high molecular weight GAG, found naturally as a component of cartilage. It is composed of repeating units of glucosamine sulfate, a GAG that is much smaller than chondroitin sulfate and much better absorbed. Chondroitin sulfate is generally poorly absorbed, anywhere from $0-18 \%$ of what is ingested. The research is mixed as far as the results of oral chondroitin sulfate on $\mathrm{OA}$ since it has to be partially digested to be absorbed. Administration of low-molecular weight chondroitin sulfate has been demonstrated to have beneficial effects on the alternative complement pathway, thus preserving chondrocytes and preventing damage to cartilage [34]. Immunoassays specific for a peptide of the alpha-helical region of type II collagen 108HRGYPGLDG116 (Coll 2-1) were used to determine the effect of chondroitin sulfate on OA. The authors used visual analog scale to determine pain, and Lequesne's Index to measure function. They concluded that chondroitin sulfate supplements positively affected OA, reducing Coll 2-1 levels, resulting in decreased pain and increased function [35]. Other studies have shown that combining chondroitin sulfate with hyaluronic acid and keratin improved OA [36]. Chondroitin sulfate supplements have been shown to inhibit NF-KB activity, thus preventing further damage to cartilage [37].

\section{Hyaluronan (Hyaluronic acid or HA)}

Hyaluronan is a GAG found in synovial joints, between layers of fascia and in loose connective tissue. It allows cartilage to imbibe water and provides an excellent medium for diffusion. By age 70, the amount of HA found in the body is estimated to be as little as $20 \%$ of that of a forty year old [38-40]. This is implicated in dry skin and poor wound healing so prevalent in the elderly, as well as accelerated rates of osteoporosis. Both oral and injectable versions of hyaluronan have been shown to be beneficial in treating OA [41-45]. In vitro experiments have shown that hyaluronan has a positive effect on the growth of chondrocytes as well [46].

\section{S-adenosylmethionine (SAMe)}

SAMe is a combination of methionine and ATP (adenosine triphosphate). It is important in cartilage in that a deficiency results in a loss of the integrity of cartilage in regard to shock absorption. Some proposed mechanisms are the decrease in TNF- $\alpha[47,48]$, increasing levels of glutathione peroxidase, signaling of proteoglycan synthesis, increased methylation of proteoglycans, and positive effects on DNA synthesis in cartilage by acting as a signal of sulfur availability $[48,49]$.

\section{Niacinamide}

There were several studies in the 1940s and 1950s by William Kaufman that reported significant benefits from supplementing with niacinamide in patients with OA. Niacinamide has been shown to prevent apoptosis of chondrocytes by inhibiting cytokine (IL-1) stimulated nitric oxide synthase [49]. This has been shown to be an important mechanism in the development of OA [49]. Administration of niacinamide in patients with OA improved joint flexibility, reduced inflammation, and reduced the need for pain medication [50]. Due to the short half-life of the vitamin, taking niacinamide in divided doses yielded the best results.

\section{Antioxidants}

The intake of carotenoids, ascorbate and vitamin $E$ have all been demonstrated to improve the symptoms of $O A$ and even to reverse the progression of the disease [51,52]. The odds of having hip OA were reduced by nearly two fold when 
the individual consumed recommended or higher amounts of vitamin C [53]. It has been demonstrated that vitamin $C$ protects chondrocytes from oxidative damage from hydrogen peroxide by regulating multiple regulatory pathways [54]. Astaxanthin, a carotenoid found in a variety of marine mammals and plants, has been shown to reduce Matrix Metalloproteinases (MMP), a substance known to degrade cartilage $[55,56]$. The carotenoids in saffron, namely crocins and crocetin, are known to prevent the expression of MMP due to IL-1 $\beta[57,58]$.

\section{Vitamin D}

According to several studies, low plasma levels of vitamin $D$ are associated with an increased risk of OA [59-61]. However, there are some studies that contradict these findings $[62,63]$. Improved outcomes following knee arthroplasty were noted after vitamin D supplementation [64]. Vitamin D has been shown to have a positive effect on the mass of the quadriceps muscles [65]. It seems that inadequate levels of vitamin $D$ contribute to the progression of $\mathrm{OA}$, but it is not clear whether supplementation is beneficial in improving symptoms in those afflicted with the disease.

\section{Vitamin K}

Low vitamin $\mathrm{K}$ status is associated with an increased incidence of OA [66-68]. The anti-inflammatory effects of vitamin $K$ are thought to play an important role in the prevention of $\mathrm{OA}$. The carboxylation of osteocalcin is dependent on vitamin K. Vitamin $\mathrm{K}$ deficiency caused serum undercarboxyled osteocalcin levels to increase. Measuring these levels has been suggested as a marker for the potential development of OA [69]. Mineralization of cartilage has been observed in osteoarthritic cartilage. Chondrocytes from osteoarthritic tissue produced significantly less amounts of matrix GLA protein, a known inhibitor of mineralization. This correlates with lower than normal vitamin $\mathrm{K}$ status [70]. A study that included 719 subjects looked at the relationship between vitamin $\mathrm{K}$ levels and $\mathrm{OA}$ and concluded that "vitamin $\mathrm{K}$ may have a protective role against knee $O \mathrm{~A}^{\text {" and that }}$ supplementing with vitamin $\mathrm{K}$ "might lead to a disease-modifying treatment" [71].

\section{Zingiber officianalis (Ginger)}

Ginger is well-known for its anti-inflammatory and anti-nausea effects. A recent study used a combination of ginger and Echinacea purpurea to treat OA patients that did not respond well to NSAIDs, and demonstrated significant improvements [72]. In several studies, ginger was shown to inhibit inflammatory cytokines and prevented the degradation of cartilage [73-75]. Even topical applications of ginger have been shown to be helpful in improving the symptoms of OA [76].

\section{Harpagophytum procumbens (Devil's Claw)}

Devil's claw is a plant native to South Africa. It is known to possess several compounds that block the expression of inflammatory cytokines [77]. Fewer than $30 \mathrm{mg}$ per day seemed to have little effect on $\mathrm{OA}$, whereas supplements containing $60 \mathrm{mg}$ or more were mildly effective in relieving the symptoms of OA [78-80].
There was one case study reporting hypertension caused by $H$. procumbens, therefore caution should be exercised when prescribing to a patient that is borderline or hypertensive [81].

\section{Boswellia serrata}

Boswellia serrata is a tree used to treat inflammatory conditions. Out of twelve boswellic acids purified from the resin of the tree that have been identified, two are of particular interest in treating chronic inflammation. KBA and AKBA have both been shown to inhibit the secretion of a variety of pro-inflammatory cytokines, including IL- 1, IL-2, IL- 6 , IFN- $-\gamma$ and TNF- $\alpha$, products of complement and inhibition of leukotrienes [82]. Two studies by the same group used an extract of Boswellia called FlexiQule, demonstrated reduction in pain and improved mobility when compared to control groups $[83,84]$. Another study reviewed several botanical medicines for the treatment of $\mathrm{OA}$ and concluded that Boswellia extracts are effective in treating OA through a number of mechanisms [85]. Yet another study looked at combining Curcumin and Boswellia proved to be more effective than a COX-2 inhibitor, celecoxib. The combination of the two herbs was without side effects [86].

\section{Curcuma longa}

There are a number of studies touting the anti-inflammatory effects of $C$. longa [87-90]. It has been well-established that $C$. longa disrupts a number of inflammatory pathways. In a study comparing $C$. longa to ibuprofen, the benefits were similar in the two treatment groups, but the curcumin-treated group had significantly less gastrointestinal symptoms [91]. Another multi-center study confirmed these results [92]. Another study deemed $C$. longa as an alternative to traditional pharmaceuticals for treating OA due to its excellent safety record and low cost [93]. Multiple studies strongly recommend the use of $C$. longa in the treatment of OA because of its long history of safety and efficacy [94-96].

\section{Proteolytic enzymes}

Papain, rutin, bromelain, trypsin and chymotrypsin are all proteolytic enzymes that are used clinically for inflammatory conditions. Papain, rutin and bromelain are from vegetable sources, and trypsin and chymotrypsin are derived from bovine or porcine pancreas. To mitigate the effects of inflammation, proteolytic enzymes must be taken away from food. Several studies looked at the efficacy and safety of proteolytic enzymes and concluded that they are as good or superior to pharmacological agents, with a superior safety record [97-101]. Two studies compared diclofenac and proteolytic enzymes and concluded that the enzyme treatment was as effective as diclofenac, but was safer to use and had a fewer side effects $[97,98]$.

\section{Summary}

Osteoarthritis is a debilitating disease that affects over a third of Americans over the age of 60 . Natural approaches to treatment of the disease and its symptoms have been shown to be effective and cost saving. Combining a diet rich in omega-3 fatty acids, 
flavonoids, and high in fibre with supplements and botanicals, has the potential of halting the progression of the disease and even reversing some of the damage to joints.

\section{Supplements}

Glucosamine sulfate: $1500 \mathrm{mg} /$ day;

Niacinamide: $500 \mathrm{mg}$ 6x/day;

Beta-carotene: 25,000 IU/day;

Vitamin C: $1000 \mathrm{mg} \mathrm{2x/day;}{ }^{*}$ Can cause loose bowels or diarrhea in high doses;

Vitamin E: 400 IU 2x/day; ${ }^{*}$ Can cause a temporary hypertension in patients who are borderline HTN;

Vitamin K: $750 \mu \mathrm{g} /$ day;

Pyridoxine $\left(\mathrm{B}_{6}\right): 50 \mathrm{mg} / \mathrm{day}$;

Pantothenic acid $\left(B_{5}\right): 30 \mathrm{mg} /$ day;
Hyaluronan: 60-100 mg 2x/day;

SAMe: $500 \mathrm{mg}$ 3x/day;

Zinc: $50 \mathrm{mg} /$ day $\mathrm{m}$; ${ }^{*}$ Must be taken with copper to avoid a copper deficiency;

Copper: 3 mg/day;

Boron: $6 \mathrm{mg} /$ day.

\section{Botanicals}

Ginger: 1000 mg 3x/day;

Devil's claw: $60 \mathrm{mg}$ of harpagoside/day;

Boswellia serrata: $400 \mathrm{mg}$ of boswellic acids 3x/day;

Curcumin: 500 mg 3x/day;

Proteolytic enzymes: mixture of bromelain/papain/rutin/trypsin/ chymotrypsin $500 \mathrm{mg} 3 \mathrm{x} /$ day on an empty stomach. 


\section{References}

1 Shrestha S, Dave AJ, Losina E, Katz JN (2016) Comparison of selfreport and objective measures of physical activity in US adults with osteoarthritis. Rheumatol Int 36: 1355-1364.

2 Wluka AE, Ding C, Wang Y, Jones G, Urquhart DM, et al. (2015) Aspirin is associated with reduced cartilage loss in knee osteoarthritis: Data from a cohort study. Maturitas 81: 394-397.

3 Ou Y, Tan C, An H, Jiang D, Quan Z, et al. (2012) Selective COX2 inhibitor ameliorates osteoarthritis by repressing apoptosis of chondrocyte. Med Sci Monit 18: BR247-BR252.

4 Brooks PM, Potter SR, Buchanan WW (1982) NSAID and osteoarthrtitis: help or hindrance. J Rheumatol 9: 3-5.

5 Bassleer C, Magotteaux J, Geenen V, Malaise M (1997) Effects of meloxicam compared to acetylsalicylic acid in human articular chondrocytes. Pharmaco 54: 49-56.

6 Lapane KL, Yang S, Driban JB, Liu SH, Dubé CE, et al. (2015) Effects of prescription nonsteroidal antiinflammatory drugs on symptoms and disease progression among patients with knee osteoarthritis. Arthritis Rheumatol 67: 724-732.

7 Sharma L, Song J, Felson DT, Cahue S, Shamiyeh E, et al. (2001) The role of knee alignment in disease progression and functional decline in knee osteoarthritis. JAMA 286: 188-195.

8 Sritharan P, Lin YC, Richardson SE, Crossley KM, Birmingham TB, et al. (2016) Musculoskeletal loading in the symptomatic and asymptomatic knees of middle-aged osteoarthritis patients. J Orthop Res.

9 Hosnijeh FS, Zuiderwijk ME, Versteeg M, Smeele HT, Hofman A, et al. (2016) Cam deformity and acetabular dysplasia as risk factors for hip osteoarthritis. Arthritis Rheumatol.

10 Abbott JH, Chapple CM, Fitzgerald GK, Fritz JM, Childs JD, et al. (2015) The Incremental Effects of Manual Therapy or Booster Sessions in Addition to Exercise Therapy for Knee Osteoarthritis: A Randomized Clinical Trial. J Orthop Sports Phys Ther 45: 975-983.

11 Dwyer L, Parkin-Smith GF, Brantingham JW, Korporaal C, Cassa TK, et al. (2015) Manual and manipulative therapy in addition to rehabilitation for osteoarthritis of the knee: assessor-blind randomized pilot trial. J Manipulative Physiol Ther 38: 1-21.

12 Romeo A, Parazza S, Boschi M, Nava T, Vanti C (2013) Manual therapy and therapeutic exercise in the treatment of osteoarthritis of the hip: a systematic review. Reumatismo 65: 63-74.

13 Pinto D, Robertson MC, Abbott JH, Hansen P, Campbell AJ (2013) MOA Trial Team, Manual therapy, exercise therapy, or both, in addition to usual care, for osteoarthritis of the hip or knee 2: economic evaluation alongside a randomized controlled trial. Osteoarthr Cartil 21: 1504-1513.

14 Bartels EM, Juhl CB, Christensen R, Hagen KB, Danneskiold-Samsøe $B$, et al. (2016) Aquatic exercise for the treatment of knee and hip osteoarthritis. Cochrane Database Syst Rev 3: CD005523.

15 Alkatan M, Baker JR, Machin DR, Park W, Akkari AS, et al. (2016) Improved Function and Reduced Pain after Swimming and Cycling Training in Patients with Osteoarthritis. J Rheumatol 43: 666-672.

16 Lu M, Su Y, Zhang Y, Zhang Z, Wang W, et al. (2015) Effectiveness of aquatic exercise for treatment of knee osteoarthritis: Systematic review and meta-analysis. Z Rheumatol 74: 543-552.

17 Hall M, Wrigley TV, Kasza J, Dobson F, Pua YH, et al. (2016) Crosssectional association between muscle strength and self-reported physical function in 195 hip osteoarthritis patients. Semin Arthritis Rheum 16: 30191-30193.

18 Loeser RF (2010) Age-related changes in the musculoskeletal system and the development of osteoarthritis. Clin Geriatr Med 26: 371-386.

19 Goldring MB (2012) Chondrogenesis, chondrocyte differentiation, and articular cartilage metabolism in health and osteoarthritis. Ther Adv Musculoskelet Dis 4: 269-285.

20 van der Esch $M$, van der Leeden $M$, Roorda LD, Lems WF, Dekker $J$ (2016) Predictors of self-reported knee instability among patients with knee osteoarthritis: results of the Amsterdam osteoarthritis cohort. Clin Rheumatol.

21 Wang F, Shi L, Xue QY (2016) Association of Metabolic Factors with Symptomatic Hand Osteoarthritis in the Chinese Han Population Aged 40 Years and above. Chin Med J (Engl) 129: 2301-2307.

22 Ribeiro M, López de Figueroa P, Blanco FJ, Mendes AF, Caramés B (2016) Insulin decreases autophagy and leads to cartilage degradation. Osteoarthr Cartil 24: 731-739.

23 Gay C, Chabaud A, Guilley E, Coudeyre E (2016) Educating patients about the benefits of physical activity and exercise for their hip and knee osteoarthritis. Systematic literature review. Ann Phys Rehabil Med 59: 174-183.

24 Veronese N, Stubbs B, Noale M, Solmi M, Luchini C, et al. (2016) Adherence to the Mediterranean diet is associated with better quality of life: data from the Osteoarthritis Initiative. Am J Clin Nutr.

25 Wang L, Ma T, Zheng Y, Lv S, Li Y, et al. (2015) Diosgenin inhibits IL-1 $\beta$-induced expression of inflammatory mediators in human osteoarthritis chondrocytes. Int J Clin Exp Pathol 8: 4830-4836.

26 Vuillermoz B, Wegrowski Y, Contet-Audonneau JL, Danoux L, Pauly $\mathrm{G}$, et al. (2005) Influence of aging on glycosaminoglycans and small leucine-rich proteoglycans production by skin fibroblasts. Mol Cell Biochem 277: 63-72.

27 Sames K, Lücht B (1991) Changes of the glycosaminoglycan metabolism in human lung fibroblasts and porcine aortic endothelium cells influenced by the number of subcultures in vitro and by lipids in the medium. Z Gerontol 24: 94-97.

28 Cao T, Li Y, Jiang L, Yuan L, Dong L, et al. (2016) Novel biologically active series of $\mathrm{N}$-acetylglucosamine derivatives for the suppressive activities on GAG release. Carbohydr Res 433: 73-79.

29 Bruyère $O$, Altman RD, Reginster JY (2016) Efficacy and safety of glucosamine sulfate in the management of osteoarthritis: Evidence from real-life setting trials and surveys. Semin Arthritis Rheum 45: S12-S17.

30 Roman-Blas JA, Castañeda S, Sánchez-Pernaute O, Largo R (2016) Herrero-Beaumont Chondroitin sulfate plus glucosamine sulfate shows no superiority over placebo in a randomized, double-blind, placebo-controlled clinical trial in patients with knee osteoarthritis. Arthritis Rheumatol.

31 Kanzaki N, Otsuka Y, Izumo T, Shibata H, Nagao H, et al. (2016) Glucosamine-containing supplement improves locomotor functions in subjects with knee pain- a pilot study of gait analysis. Clin Interv Aging 11: 835-841.

32 Shaughnessy AF (2016) Chondroitin/Glucosamine Equal to Celecoxib for Knee Osteoarthritis. Am Fam Physician 93: 1032.

33 Peluso R, Caso F, Costa L, Sorbo D, Carraturo N, et al. (2016) Mudbath therapy and oral glucosamine sulfate in patients with knee osteoarthritis: a randomized, controlled, crossover study. Clin Exp Rheumatol 34: 618-624. 
34 Li L, Li Y, Feng D, Xu L, Yin F, et al. (2016) Preparation of Low Molecular Weight Chondroitin Sulfates, Screening of a High Anti-Complement Capacity of Low Molecular Weight Chondroitin Sulfate and Its Biological Activity Studies in Attenuating Osteoarthritis. Int J Mol Sci 17.

35 Möller I, Gharbi M, Martinez Serrano H, Herrero Barbero M, Verges Milano J, et al. (2016) Effect of chondroitin sulfate on soluble biomarkers of osteoarthritis: a method to analyze and interpret the results from an open-label trial in unilateral knee osteoarthritis patients. BMC Musculoskelet Disord 17: 416.

36 Galluccio F, Barskova T, Cerinic MM (2015) Short-term effect of the combination of hyaluronic acid, chondroitin sulfate, and keratin matrix on early symptomatic knee osteoarthritis. Eur J Rheumatol 2: 106-108.

37 Stabler TV, Huang Z, Montell E, Vergés J, Kraus VB (2016) Chondroitin sulphate inhibits NF-KB activity induced by interaction of pathogenic and damage associated molecules. Osteoarthr Cartil, pp: S1063-S4584.

38 Sluke G, Schachtschabel DO, Wever J (1981) Age-related changes in the distribution pattern of glycosaminoglycans synthesized by cultured human diploid fibroblasts (WI-38). Mech Ageing Dev 16: 19-27.

39 Komosinska-Vassev K, Olczyk P, Winsz-Szczotka K, Kuznik-Trocha K, Klimek K, et al. (2012) Age- and gender-related alteration in plasma advanced oxidation protein products (AOPP) and glycosaminoglycan (GAG) concentrations in physiological ageing. Clin Chem Lab Med 50: 557-563.

40 Oh JH, Kim YK, Jung JY, Shin JE, Kim KH, et al. (2011) Intrinsic agingand photoaging-dependent level changes of glycosaminoglycans and their correlation with water content in human skin. J Dermatol Sci 62: 192-201.

41 Morgan TK, Jensen E, Lim J, Riggs R (2015) Image-Guided Hyaluronic Acid Injection and Knee Bracing Significantly Improve Clinical Outcomes for High-Grade Osteoarthritis. Sports Med Open 1: 31.

42 Bannuru RR, Brodie CR, Sullivan MC, McAlindon TE (2016) Safety of Repeated Injections of Sodium Hyaluronate (SUPARTZ) for Knee Osteoarthritis: A Systematic Review and Meta-Analysis. Cartilage 7: 322-332.

43 Conrozier T, Bozgan AM, Bossert M, Sondag M, Lohse-Walliser A, et al. (2016) Standardized Follow-up of Patients with Symptomatic Knee Osteoarthritis Treated with a Single Intra-articular Injection of a Combination of Cross-Linked Hyaluronic Acid and Mannitol. Clin Med Insights Arthr Musculoskel Disord 9: 175-179.

44 Ricci M, Micheloni GM, Berti M, Perusi F, Sambugaro E, et al. (2016) Clinical comparison of oral administration and viscosupplementation of hyaluronic acid (HA) in early knee osteoarthritis. Musculoskel Surg.

45 Weick JW, Bawa HS, DirschI DR (2016) Hyaluronic Acid Injections for Treatment of Advanced Osteoarthritis of the Knee: Utilization and Cost in a National Population Sample. J Bone Joint Surg Am 98: 14291435.

46 Bauer C, Niculescu-Morzsa E, Jeyakumar V, Kern D, Späth SS, et al. (2016) Chondroprotective effect of high-molecular-weight hyaluronic acid on osteoarthritic chondrocytes in a co-cultivation inflammation model with M1 macrophages. J Inflamm (Lond) 13: 31.

47 Stanic I, Facchini A, Borzì RM, Vitellozzi R, Stefanelli C, et al. (2006) Polyamine depletion inhibits apoptosis following blocking of survival pathways in human chondrocytes stimulated by tumor necrosis factor-alpha. J Cell Physiol 206: 138-146.
48 Hosea Blewett HJ (2008) Exploring the mechanisms behind S-adenosylmethionine (SAMe) in the treatment of osteoarthritis. Crit Rev Food Sci Nutr 48: 458-63.

49 McCarty MF, Russell AL (1999) Niacinamide therapy for osteoarthritis-does it inhibit nitric oxide synthase induction by interleukin 1 in chondrocytes? Med Hypotheses 53: 350-360.

50 Jonas WB, Rapoza CP, Blair WF (1996) The effect of niacinamide on osteoarthritis: a pilot study. Inflamm Res 45: 330-334.

51 Wang Y, Smith S, Teichtahl AJ, Hodge AM, Wluka AE, et al. (2016) Association Between Dietary Intake of Antioxidants and Prevalence of Femoral Head Cartilage Defects and Bone Marrow Lesions in Community-based Adults. J Rheumatol 43: 1885-1890.

52 Li H, Zeng C, Wei J, Yang T, Gao SG, et al. (2016) Associations between dietary antioxidants intake and radiographic knee osteoarthritis. Clin Rheumatol 35: 1585-1592.

53 Plotnikoff R, Karunamuni N, Lytvyak E, Penfold C, Schopflocher D, et al. (2015) Osteoarthritis prevalence and modifiable factors: a population study. BMC Public Health 15: 1195.

54 Chang Z, Huo L, Li P, Wu Y, Zhang P (2015) Ascorbic acid provides protection for human chondrocytes against oxidative stress. Mol Med Rep 12: 7086-7092.

55 Huang LJ, Chen WP (2015) Astaxanthin ameliorates cartilage damage in experimental osteoarthritis. Mod Rheumatol 25: 768-771.

56 Chen WP, Xiong Y, Shi YX, Hu PF, Bao JP, et al. (2014) Astaxanthin reduces matrix metalloproteinase expression in human chondrocytes. Int Immunopharmacol 19: 174-177.

57 Ding Q, Zhong H, Qi Y, Cheng Y, Li W, et al. (2013) Anti-arthritic effects of crocin in interleukin-1 $\beta$-treated articular chondrocytes and cartilage in a rabbit osteoarthritic model. Inflamm Res 62: 17-25.

58 Mashmoul M, Azlan A, Khaza'ai H, Yusof BN, Noor SM (2013) Saffron: A Natural Potent Antioxidant as a Promising Anti-Obesity Drug. Antioxidants (Basel) 2: 293-308.

59 Pascual-Garrido C, Angeline ME, Ma R, Chahla J, Voigt C, et al. (2016) Low Levels of Vitamin $D$ have a Deleterious Effect on the Articular Cartilage in a Rat Model. HSS J 12: 150-157.

60 Bassiouni H, Aly H, Zaky K, Abaza N, Bardin T (2016) Probing The Relation Between Vitamin D Deficiency and Progression of Medial Femoro-tibial Osteoarthitis of the knee. Curr Rheumatol Rev.

61 Veronese N, Maggi S, Noale M, De Rui M, Bolzetta F, et al. (2015) Serum 25-Hydroxyvitamin D and Osteoarthritis in Older People: The Progetto Veneto Anziani Study. Rejuvenation Res 18: 543-553.

62 Jin X, Jones G, Cicuttini F, Wluka A, Zhu Z, et al. (2016) Effect of Vitamin D Supplementation on Tibial Cartilage Volume and Knee Pain among Patients With Symptomatic Knee Osteoarthritis: A Randomized Clinical Trial. JAMA 315: 1005-1013.

63 Lee A, Lee JE (2016) Vitamin D and the characteristics associated with risk for knee pain among Korean older adults: Findings from a nationally representative survey. Geriatr Gerontol Int.

64 Maniar RN, Patil AM, Maniar AR, Gangaraju B, Singh J (2016) Effect of Preoperative Vitamin D Levels on Functional Performance after Total Knee Arthroplasty. Clin Orthop Surg 8: 153-156.

65 Koeckhoven E, van der Leeden M, Roorda LD, van Schoor NM, Lips P, et al. (2016) The Association between Serum 25-hydroxy Vitamin D Level and Upper Leg Strength in Patients with Knee Osteoarthritis: Results of the Amsterdam Osteoarthritis Cohort. J Rheumatol 43: 1400-1405. 
66 Harshman SG, Shea MK (2016) The Role of Vitamin K in Chronic Aging Diseases: Inflammation, Cardiovascular Disease, and Osteoarthritis. Curr Nutr Rep 5: 90-98.

67 Shea MK, Kritchevsky SB, Hsu FC, Nevitt M, Booth SL, et al. (2015) The association between vitamin $\mathrm{K}$ status and knee osteoarthritis features in older adults: the Health, Aging and Body Composition Study. Osteoarthr Cartil 23: 370-378.

68 Misra D, Booth SL, Tolstykh I, Felson DT, Nevitt MC, et al. (2013) Vitamin K deficiency is associated with incident knee osteoarthritis. Am J Med 126: 243-248.

69 Naito K, Watari T, Obayashi O, Katsube S, Nagaoka I, et al. (2012) Relationship between serum undercarboxylated osteocalcin and hyaluronan levels in patients with bilateral knee osteoarthritis. Int J Mol Med 29: 756-760.

70 Wallin R, Schurgers LJ, Loeser RF (2010) Biosynthesis of the vitamin K-dependent matrix Gla protein (MGP) in chondrocytes: a fetuinMGP protein complex is assembled in vesicles shed from normal but not from osteoarthritic chondrocytes. Osteoarthr Cartil 18: 10961103.

71 Oka H, Akune T, Muraki S, En-yo Y, Yoshida M, et al. (2009) Association of low dietary vitamin $\mathrm{K}$ intake with radiographic knee osteoarthritis in the Japanese elderly population: dietary survey in a populationbased cohort of the ROAD study. J Orthop Sci 14: 687-692.

72 Rondanelli $M$, Riva A, Morazzoni $P$, Allegrini $P$, Faliva MA, et al. (2016) The effect and safety of highly standardized Ginger (Zingiber officinale) and Echinacea (Echinacea angustifolia) extract supplementation on inflammation and chronic pain in NSAIDs poor responders. A pilot study in subjects with knee arthrosis. Nat Prod Res 13: 1-5.

73 Ruangsuriya J, Budprom P, Viriyakhasem N, Kongdang $P$, Chokchaitaweesuk C, et al. (2016) Suppression of Cartilage Degradation by Zingerone Involving the p38 and JNK MAPK Signaling Pathway. Planta Med.

74 Mozaffari-Khosravi H, Naderi Z, Dehghan A, Nadjarzadeh A, Fallah Huseini H (2016) Effect of Ginger Supplementation on Proinflammatory Cytokines in Older Patients with Osteoarthritis: Outcomes of a Randomized Controlled Clinical Trial. J Nutr Gerontol Geriatr 35: 209-218.

75 Naderi Z, Mozaffari-Khosravi H, Dehghan A, Nadjarzadeh A, Husein HF (2015) Effect of ginger powder supplementation on nitric oxide and C-reactive protein in elderly knee osteoarthritis patients: A 12week double-blind randomized placebo-controlled clinical trial. $J$ Tradit Complement Med 6: 199-203.

76 Amorndoljai P, Taneepanichskul S, Niempoog S, Nimmannit U (2015) Improving of Knee Osteoarthritic Symptom by the Local Application of Ginger Extract Nanoparticles: A Preliminary Report with Short Term Follow-Up. J Med Assoc Thai 98: 871-877.

77 Fiebich BL, Muñoz E, Rose T, Weiss G, McGregor GP (2012) Molecular targets of the antiinflammatory Harpagophytum procumbens (devil's claw): inhibition of TNF $\alpha$ and COX-2 gene expression by preventing activation of AP-1. Phytother Res 26: 806-811.

78 Cameron M, Gagnier JJ, Little CV, Parsons TJ, Blümle A, et al. (2009) Evidence of effectiveness of herbal medicinal products in the treatment of arthritis. Part I: Osteoarthritis. Phytother Res 23: 14971515

79 Sanders M, Grundmann O (2011) The use of glucosamine, devil's claw (Harpagophytum procumbens), and acupuncture as complementary and alternative treatments for osteoarthritis. Altern Med Rev 16: 228-238.

80 Akhtar N, Haqqi TM (2012) Current nutraceuticals in the management of osteoarthritis: a review. Ther Adv Musculoskelet Dis 4: 181-207.

81 Cuspidi C, Sala C, Tadic M, Grassi G, Mancia G (2015) Systemic Hypertension Induced by Harpagophytum procumbens (devil's claw): A Case Report. J Clin Hypertens (Greenwich) 17: 908-910.

82 Ammon HP (2016) Boswellic Acids and Their Role in Chronic Inflammatory Diseases. Adv Exp Med Biol 928: 291-327.

83 Belcaro G, Dugall M, Luzzi R, Ledda A, Pellegrini L, et al. (2015) Management of osteoarthritis (OA) with the pharma-standard supplement FlexiQule (Boswellia): a 12-week registry. Minerva Gastroenterol Dietol.

84 Belcaro G, Dugall M, Luzzi R, Ledda A, Pellegrini L, et al. (2015) FlexiQule (Boswellia extract) in the supplementary management of osteoarthritis: a supplement registry. Curr Rheumatol Rep 17: 54.

85 Walzer SM, Weinmann D, Toegel S (2015) Medical Plant Extracts for Treating Knee Osteoarthritis: a Snapshot of Recent Clinical Trials and Their Biological Background. Curr Rheumatol Rep 17: 54.

86 Srivastava S, Saksena AK, Khattri S, Kumar S, Dagur RS (2016) Curcuma longa extract reduces inflammatory and oxidative stress biomarkers in osteoarthritis of knee: a four-month, double-blind, randomized, placebo-controlled trial. Inflammopharmacology.

87 Chin KY (2016) The spice for joint inflammation: anti-inflammatory role of curcumin in treating osteoarthritis. Drug Des Devel Ther 10: 3029-3042.

88 Daily JW, Yang M, Park S (2016) Efficacy of Turmeric Extracts and Curcumin for Alleviating the Symptoms of Joint Arthritis: A Systematic Review and Meta-Analysis of Randomized Clinical Trials. J Med Food 19: 717-729.

89 Perkins K, Sahy W, Beckett RD (2016) Efficacy of Curcuma for Treatment of Osteoarthritis. J Evid Based Complementary Altern Med.

90 Panahi Y, Alishiri GH, Parvin S, Sahebkar A (2016) Mitigation of Systemic Oxidative Stress by Curcuminoids in Osteoarthritis: Results of a Randomized Controlled Trial. J Diet Suppl 13: 209-220.

91 Ross SM (2016) Turmeric (Curcuma longa): Effects of Curcuma longa Extracts Compared with Ibuprofen for Reduction of Pain and Functional Improvement in Patients with Knee Osteoarthritis. Holist Nurs Pract 30: 183-186.

92 Kuptniratsaikul V, Dajpratham P, Taechaarpornkul W, Buntragulpoontawee M, Lukkanapichonchut $\mathrm{P}$, et al. (2014) Efficacy and safety of Curcuma domestica extracts compared with ibuprofen in patients with knee osteoarthritis: a multicenter study. Clin Interv Aging 9: 451-458.

93 Aggarwal BB, Gupta SC, Sung B (2013) Curcumin: an orally bioavailable blocker of TNF and other pro-inflammatory biomarkers. Br J Pharmacol 169: 1672-1692.

94 Madhu K, Chanda K, Saji MJ (2013) Safety and efficacy of Curcuma longa extract in the treatment of painful knee osteoarthritis: a randomized placebo-controlled trial. Inflammopharmacology 21: 129-136.

95 Pinsornsak P, Niempoog S (2012) The efficacy of Curcuma Longa L. extract as an adjuvant therapy in primary knee osteoarthritis: a randomized control trial. J Med Assoc Thai 95: S51-S58. 
96 Kuptniratsaikul V, Thanakhumtorn S, Chinswangwatanakul P, Wattanamongkonsil L, Thamlikitkul V (2009) Efficacy and safety of Curcuma domestica extracts in patients with knee osteoarthritis. J Altern Complement Med 15: 891-897.

97 Ueberall MA, Mueller-Schwefe GH, Wigand R, Essner U (2016) Efficacy, tolerability, and safety of an oral enzyme combination vs diclofenac in osteoarthritis of the knee: results of an individual patient-level pooled reanalysis of data from six randomized controlled trials. J Pain Res 9: 941-961.

98 Akhtar NM, Naseer R, Farooqi AZ, Aziz W, Nazir M (2004) Oral enzyme combination versus diclofenac in the treatment of osteoarthritis of the knee-a double-blind prospective randomized study. Clin Rheumatol 23: 410-415.

99 Kasemsuk T, Saengpetch N, Sibmooh N, Unchern S (2016) Improved WOMAC score following 16-week treatment with bromelain for knee osteoarthritis. Clin Rheumatol 35: 2531-2540.

100 Pavan R, Jain S, Shraddha, Kumar A (2012) Properties and therapeutic application of bromelain: a review. Biotechnol Res Int 2012: 976203.

101 Brien S, Lewith G, Walker AF, Middleton R, Prescott P, et al. (2006) Bromelain as an adjunctive treatment for moderate-to-severe osteoarthritis of the knee: a randomized placebo-controlled pilot study. QJM 99: 841-850. 